\title{
CORRECTION
}

\section{Correction: Early intra-intensive care unit psychological intervention promotes recovery from post traumatic stress disorders, anxiety and depression symptoms in critically ill patients}

\author{
Adriano Peris', Manuela Bonizzoli', Dario lozzelli², Maria Luisa Migliaccio', Giovanni Zagli*1, Alberto Bacchereti², \\ Marta Debolini², Elisetta Vannini', Massimo Solaro', Ilaria Balzi', Elisa Bendoni', Ilaria Bacchi', Monica Trevisan', \\ Valtere Giovannini ${ }^{3}$ and Laura Belloni
}

See related research by Peris et al., http://ccforum.com/content/15/1/R41

Following publication of our article [1], we noted that we inadvertently failed to include Dr Monica Trevisan as a coauthor. Dr Trevisan has now been added, and the Authors' contributions section has been modified accordingly.

\section{Competing interests}

The authors have no competing interests.

\section{Author contributions}

AP, VG and LB organized the Clinical Psychological Service. AP, MB, MLM, DI and $A B$ designed the study. $A P, M B$ and $G Z$ reviewed the literature. MLM, $A B$, $M D, D I, E V, M S, I B, E B, M T$ and $I B$ collected the data. $D I, A B$ and $M D$ performed clinical psychologist interventions. MLM, AB, MD, DI, EV, MS, IB, EB and IB performed follow-up examinations. GZ performed statistical analysis. AP, DI, AB and GZ wrote the draft. All Authors revised the manuscript and approved the final version.

\section{Author details}

'Anaesthesia and Intensive Care Unit of Emergency Department, Careggi Teaching Hospital, Largo Brambilla 3, I-50139 Florence, Italy. ${ }^{2}$ Regional.
Referral Center on Critical Human Relations, Careggi Teaching Hospital, Largo Brambilla 3, I-50139 Florence, Italy. ${ }^{3}$ Medical Director of Careggi Teaching Hospital, Largo Brambilla 3, I-50139 Florence, Italy.

Published: 18 April 2011

\section{References}

1. Peris A, Bonizzoli M, lozzelli D, Migliaccio ML, Zagli G, Bacchereti A, Debolini M, Vannini E, Solaro M, Balzi I, Bendoni E, Bacchi I, Giovannini V, Belloni L: Early intra-intensive care unit psychological intervention promotes recovery from post traumatic stress disorders, anxiety and depression symptoms in critically ill patients. Critical Care 2011, 15:R41.

\section{doi:10.1186/cc10133}

Cite this article as: Peris $A$, et al.: Correction: Early intra-intensive care unit psychological intervention promotes recovery from post traumatic stress disorders, anxiety and depression symptoms in critically ill patients. Critical Care 2011, 15:418.
*Correspondence: giovanni.zagli@unifi.it

'Anaesthesia and Intensive Care Unit of Emergency Department, Careggi Teaching Hospital, Largo Brambilla 3, I-50139 Florence, Italy

Full list of author information is available at the end of the article 